\title{
Warehouse Selection Problem Solution by Using Proper MCDM Process
}

\author{
Md. Al Amin, Apurba Das*, Sumit Roy, Md. Imran Shikdar \\ Department of Industrial Engineering and Management, Khulna University of Engineering \& Technology (KUET), Khulna, Bangladesh \\ Email address: \\ dasapu.2009@gmail.com (A. Das) \\ ${ }^{*}$ Corresponding author \\ To cite this article: \\ Md. Al Amin, Apurba Das, Sumit Roy, Md. Imran Shikdar. Warehouse Selection Problem Solution by Using Proper MCDM Process. \\ International Journal of Science and Qualitative Analysis. Vol. 5, No. 2, 2019, pp. 43-51. doi: 10.11648/j.ijsqa.20190502.13
}

Received: October 3, 2019; Accepted: October 31, 2019; Published: December 2, 2019

\begin{abstract}
The most efficient warehousing selection has become one of the significant logistics activities. The main objective of this paper is to select the efficient warehouse by using proper MCDM (Multi Criteria Decision Making) process against some specified criteria. This paper exhumes to explore the possibility of using several multi criteria decision making processes in warehouse location problem. This survey work introduces MCDM process in many domains to pick the best alternative from where different scope, weight for many criteria are explored. Among various methods, it is found that, by the means of the AHP and TOPSIS method, the evaluation criteria with references to the concerned goal and characteristics with respect to analogous criteria. A case study has been performed by selected MCDM (AHP, TOPSIS) process for analysing collected data. Before going for the calculation this research has done a survey by asking some question to concerned person regarding warehouse selection. From case study, among five warehouses it is found that the first warehouse is suitable which accomplishes all criteria. A validation test for AHP has been performed to verify the result obtained which also supports the result. Finally, this research paper will help to select efficient warehouse and will improve the logistics system.
\end{abstract}

Keywords: MCDM Process, AHP, TOPSIS, Warehouse Selection

\section{Introduction}

MCDM or multi criteria decision making process are of various kinds they are used for the selection of various kinds. In this research work the processes used are AHP, TOPSIS. TOPSIS assumes that each criterion has a tendency that allows its importance to increase or decrease which in turn can be used to determine the ideal best and ideal worst situation. Then the closeness to ideal negative and ideal positive value is determined which can give the ideal solution. On the other hand Brown Gibson does the same as AHP only it works differently while working with subjective factor than it works with objective factor.

This research work works in two ways. Firstly, it determines which MCDM process is suitable for which kind of situation and secondly and more importantly it provides a valid example of how an MCDM process is used. In the case of this research work the example is about choosing one warehouse out of three. The processes used in order to choose the warehouse are AHP, TOPSIS [1].

The main importance of the proposed research work lie in its methodology. Meaning the importance can be derived from the objective of the research work. So in order to understand why this particular research work is important the objective of the work needs to be understood. The main objectives of the research work are that after the evaluation of all the MCDM processes in a systematic way, which process needs to be implemented for a particular situation can be understood. Thus the level of blunder can be reduced to an extent. Because not all MCDM processes are applicable for a certain circumstance. One of the objectives of the research work was to find out which MCDM method is applicable for selecting a warehouse location. The way this research work planned to fulfil this objective is by thoroughly studying the MCDM methods and thus finding out which one is useful for the aforementioned circumstance namely the selection of warehouse.

Other objective of this research work was to implement the MCDM method in a systematic way. After fulfilling the first 
objective we were left with a few processes that can make difficult decisions. This left us with a more important objective yet to be fulfilled - that objective being making the decision by employing the selected methods. The selected methods' process was learnt by studying various research work of the similar kind. The data was mainly gathered from several experts of the field. However the importance of the research work can be derived from the objectives described above. The main importance being to our knowledge no other research work has studied these particular MCDM processes for such kind of circumstances. This makes this research work particularly important.

Another important factor associated with this particular research work is that this work actually showed the whole calculation and mathematical formulations associated with the MCDM processes. Both of which are both difficult to find. So the inclusion of the calculation and mathematical formulation made this research work all the more important. Since this work actually shows how difficult decision making can be implemented, it can be a pioneer for the researchers who want to make such decisions in the future and for industries who share the same kind of circumstances as this research. A very important observation in the case of choice of warehouses is that the chosen one is almost exclusively the most optimum one. The chosen one is most beneficial while considering all the conceivable factors. So the future value will be less for all the chosen one. Also it will be beneficial according to other factors as well. All in all it will be the optimum choice. So the industry will also be benefitted because of the decision.

While performing this research work in the calculation phase a few models were made for the convenience of data analysis. The models were basically a few excel sheets each devoted for one MCDM method. The importance associated with these 'models' are that by just changing the data in the designated area one can calculate the decision easily. These models can come to everyone's aid who want to perform research works such as this in the future. Another importance regarding this research work is that, after reading this report one can very easily identify the strengths and weaknesses of every MCDM processes. Also another important factor associated with this research work is that this research work works with AHP, TOPSIS method for selecting a location. Although these aforementioned methods are particularly important for the selection of a location much like warehouse, no research work has gone on to provide analysis in those methods. But after this research work that problem to a great extent will be solved.

In 2011, Researchers dealt with three multi criteria decision making process. First this paper comparatively described the three multi criteria decision making process namely TOPSIS (technique for order of preference by similarity to ideal solution), ELECTRE and grey theory. Then the reason behind choosing each decision making process was described. After that the main calculation was done. After considering various alternatives it reached the conclusion of most optimized warehouse location in Istanbul,
Turkey [2]. A paper work regarding solving warehouse location selection problem in a retail store has been done in China. First the paper established warehouse location selection to be one of the most important logistic activity. Then the paper describes the steps that have to be followed in order to make sure that AHP model is utilized in a proper fashion. Selecting criteria and pairwise comparison are important steps among them. In this case there were three location options to choose from and after that the calculation associated with AHP takes place. Again the same calculation is done in the center of gravity method. In both the cases same result occurs. After that the writer comes to the conclusion by calculating the consistency index. Which was very low proving the authenticity of the calculation [3]. A research work about how AHP can be used for the selection of location of a retail store has been done. The paper first determines the selection criteria associated with the particular store location. After a few generalized talk about AHP the paper goes on to calculate in the aforementioned process to determine the store location. There were five alternatives in this particular case. Then the paper introduces level of importance for the selected criteria and sub criteria. After that the paper mathematically analyzes AHP. Mathematical formulation for normalization, weight calculation, consistency check are all introduced after that. After that the paper indulges to the real calculation. The weight for all the sub criteria (attribute in this case) are determined. The weight of all the criteria are also determined. From that the priority of the three store location are selected and one of them is selected [4]. This paper argues that vendor is an extremely important aspect of supply chain management. This paper starts off by introducing the three alternatives. One of the five alternatives is chosen based on five criteria. Here the five criteria that influence the selection of a vendor for business transaction are cost, relationship with the parent industry, agility, risk avoidance and quality. According to the paper all the five criteria are selected based on experts on this particular field [5].

Researchers survey about the importance of MCDM processes and they deals with various papers of the same nature to find out the problems and the advantages associated with each MCDM process. Another important aspect of this paper is this paper found out the several fields where these processes can be implemented. The main MCDM processes this research paper works with are AHP promethee, ELECTRE, TOPSIS and grey theory. This paper gains knowledge through the use of survey. This paper is basically an extended form of a literature review [1]. The problem of which multi criteria decision making process is actually important in which circumstances were solved in 2013. This paper also determines the advantages and disadvantages of these MCDM processes. The methods in contention in this paper are various in nature. For example, this paper deals with AHP, FAHP, SAW, goal programming etc [6].

The location of a distribution center was determined in Serbia using fuzzy AHP. In order to perform the calculation of fuzzy AHP as many as six factors were selected in this 
paper. These factors were again divided in two portions. There were qualitative factors and quantitative factors. The former of the two is calculable and later is not so. Again each factor was divided among many sub factors. The sub factors are quite similar to sub criteria in AHP. Anyway after determining these factors and sub factors the main calculation is executed. And after that the weights of several sub factors are determined, and from the weights the priority of several criteria can be determined. Again in this paper no justification for use of the FAHP has been given. Then the alternatives were also ranked using the same principle. There were four alternatives to choose from in the paper. So basically the main positive points of the paper are the work with several criteria and alternatives. Also the documentation of mathematical formulation is another positive factor of this paper [7]. Their research work assessed that selection of location is an extremely important phenomenon for the implementation of which several options have to be entertained. This paper ends up merging two very different processes. First it determines the criteria weight using AHP and after that this paper evaluates the alternatives at hand. And after that the final ranking is also determined and from that the ranking mentioned above optimum solution can be gained. Here it must be noted that the weapon selection process has three stages. The first step is very much about gathering data and alternatives. The second step is about evaluating AHP and determining criteria weight. And subsequently the third one is about implementing Fuzzy TOPSIS to finally determine the optimum the weapon [8]. The research work tinker with the idea of using multi criteria decision making processes for the evaluation and eventual selection of contractors. In order to achieve said goals this research work uses such methodologies as AHP and TOPSIS. This research work identifies nine criteria and thirty one sub criteria that affect the selection of said contractor. After that this paper aims to establish a proper way of conducting the methodology. The steps of the methodology comprise of assigning weights to the criteria and sub criteria alike and after that according to the weights assigned the result was calculated according to the fuzzy TOPSIS method so that the achieved value can be verified. [9]

These research works reviewed above have one aspect in common- all of them have either performed an analysis of MCDM processes or implemented some of the MCDM processes. For example, Researchers perform MCDM processes without finding out which process is suitable for which circumstances. [8] On the other hand, a researcher perform only an analysis of several MCDM processes without implementing any of them. This is the gap this research work wished to fill. This research work managed to analyse several MCDM processes first to determine appropriate process for certain circumstances and then performed the suitable processes for the problem at hand. [10]

Stochastic multi-criteria decision-making approach which was studied for selecting the proper warehouse from various seller region for a supermarket in Turkey. They used stochastic analytic hierarchy process (SAHP) method to solute this problem while ranking was made and evaluated by fuzzy VIKOR [15]. In 2016 researchers worked with the subjective and objective factors and mentioned about three extended fuzzy MCDM methodologies. They measured the factors by Brown and Gibson model [16]. An experiment was made on selecting the location of Warehouse in humanitarian logistics (HL). They made a case study from Turkish humanitarian relief organization. They expanded Buckley's ordinary fuzzy AHP method to its hesitant fuzzy version [17]. In order to improve the supply chain of a Chemical Industry, they tried to find the proper location for warehouse by using MCDM process. They found eleven crucial parameters and after analyzing them they sum up to four factors [18].

\section{Methodology}

\subsection{Problem Identification and Solution Outline}

The aforementioned garments industry has five options in its hand for the creation of a warehouse for finished goods. In this case the finished goods are cloth. The main problem is which one of this five options should be selected. The warehouse options will be called as warehouse 1 , warehouse 2 , warehouse 3 , warehouse 4 , warehouse 5 henceforth. In order to install the warehouses, the industry will need to employ 6,8 and 9 workers respectively. The distinguishing cost for the selection of the warehouses lie in the labor cost as all other costs will be similar. The warehouses will be able to hold 80000,90000 and 95000 unit items respectively. The distance from the main factory is 210 meters, 230 meters and 250 meters respectively. The problem's first part is to identify the most suitable MCDM process for the selection of the warehouse and the next part of the problem is to actually find out which one of the five warehouses would be the ideal choice for the aforementioned circumstances according to the previously found MCDM processes. Eventually the comparison of the processes. The first part of the problem will be solved by using several research papers of the same kind in order to finding out which of the MCDM process will be suitable for the solution of the problem. The next part of the problem is more mathematical than analytical. The solution of the next part of the problem consists of using the previously found MCDM process and implementing them to select the right warehouse and in the end comparing the methods.

\subsection{Different MCDM Processes Application and Their Criteria}

While performing these processes many criteria will be selected as participating factors for selection of warehouse. These criteria were preliminarily selected using several research papers and then by asking expert advice these criteria were finalized. Now that the problem and the outline of the solution have been discussed the solution can be implemented. 
Table 1. Analysis of different MCDM processes.

\begin{tabular}{|c|c|c|c|}
\hline MCDM process & Advantage & Disadvantage & Application \\
\hline ELECTRE & $\begin{array}{l}\text { One of the very few processes that takes } \\
\text { uncertainty into account [6] }\end{array}$ & $\begin{array}{l}\text { Ancient process, result is not } \\
\text { understandable for common people } \\
\text { [6] }\end{array}$ & $\begin{array}{l}\text { Transportation problem, location } \\
\text { problem [6] }\end{array}$ \\
\hline AHP & $\begin{array}{l}\text { Easy to understand, most suited for } \\
\text { small number of criteria and options [6] }\end{array}$ & $\begin{array}{l}\text { Not applicable when number of } \\
\text { criteria or number of alternatives is } \\
\text { too many. }\end{array}$ & $\begin{array}{l}\text { Corporate policy, supply chain } \\
\text { strategy, location selection }[6]\end{array}$ \\
\hline ANP & $\begin{array}{l}\text { Feedback is taken and priorities are } \\
\text { improved, very modern in naturre [1] }\end{array}$ & $\begin{array}{l}\text { Takes a lot of time, subjective factors } \\
\text { are not used, psychology is not } \\
\text { important [1] }\end{array}$ & $\begin{array}{l}\text { So far its appliction limits are } \\
\text { unknown }\end{array}$ \\
\hline TOPSIS & $\begin{array}{l}\text { Can be used in a large number of fields, } \\
\text { can handle large number of variables } \\
\text { and criteria [10] }\end{array}$ & $\begin{array}{l}\text { Doesn't work if the number of criteria } \\
\text { or the number of alternatives is too } \\
\text { low [2] }\end{array}$ & $\begin{array}{l}\text { Water resource, supply chain and } \\
\text { logistics, energy, human factor, } \\
\text { health and safety, environment) } \\
{[10]}\end{array}$ \\
\hline Grey Theory & Very precise data needed & Optimal solution is not selected [1] & $\begin{array}{l}\text { It is used when the data is } \\
\text { incomplete [1] }\end{array}$ \\
\hline ELECTTRE I, II and III & - & - & $\begin{array}{l}\text { These methods are basically based } \\
\text { on the user's choice. These are not } \\
\text { specific methods. }\end{array}$ \\
\hline $\begin{array}{l}\text { Weighted sum method } \\
\text { (WSM) }\end{array}$ & $\begin{array}{l}\text { Good for using in a single dimensional } \\
\text { problem }\end{array}$ & $\begin{array}{l}\text { Difficulty in multi-dimensional } \\
\text { problems [1] }\end{array}$ & $\begin{array}{l}\text { Any problem considering the } \\
\text { problem is not multi-dimensional }\end{array}$ \\
\hline $\begin{array}{l}\text { Simple Additive Weighting } \\
\text { (SAW) }\end{array}$ & $\begin{array}{l}\text { No complex computer program } \\
\text { required, Simple calculation, [6] }\end{array}$ & $\begin{array}{l}\text { The solution is sometimes } \\
\text { inconceivable according to common } \\
\text { sense. [6] }\end{array}$ & $\begin{array}{l}\text { Financial problems, business } \\
\text { management and water } \\
\text { management }\end{array}$ \\
\hline PROMETHEE & $\begin{array}{l}\text { Easy to use, no assumption related to } \\
\text { selection of criteria is required [6] }\end{array}$ & $\begin{array}{l}\text { No specific process for assigning the } \\
\text { weight [6] }\end{array}$ & $\begin{array}{l}\text { "Environmental, hydrology, water } \\
\text { management, business and finance, } \\
\text { chemistry, logistics and } \\
\text { transportation" [6] }\end{array}$ \\
\hline Fuzzy theories & $\begin{array}{l}\text { Can take into account insufficient } \\
\text { information and work accordingly, } \\
\text { works even if the input is insufficient. }\end{array}$ & Not applicable for binary problems. & $\begin{array}{l}\text { Supply chain management, } \\
\text { logistics, water resource, location } \\
\text { problem, environmental hydrology }\end{array}$ \\
\hline $\begin{array}{l}\text { Simple Multi Attribute } \\
\text { Rating Technique (SMART) }\end{array}$ & Simple process & $\begin{array}{l}\text { Often regarded as good guess rather } \\
\text { than a good thought process }\end{array}$ & $\begin{array}{l}\text { Environment, construction, water } \\
\text { resource. }\end{array}$ \\
\hline $\begin{array}{l}\text { Multi-Attribute Utility } \\
\text { Theory (MAUT) }\end{array}$ & can deal with uncertainty & $\begin{array}{l}\text { A large quantity of data is required for } \\
\text { the calculation to be precise }\end{array}$ & $\begin{array}{l}\text { Economics, finance, actuarial, water } \\
\text { management, energy management, } \\
\text { agriculture }\end{array}$ \\
\hline $\begin{array}{l}\text { Case Based Reasoning } \\
\text { (CBR) }\end{array}$ & $\begin{array}{l}\text { Can be changed according to the change } \\
\text { in the circumstances. }\end{array}$ & Cannot deal with inconsistent data & $\begin{array}{l}\text { "Businesses, vehicle insurance, } \\
\text { medicine, and engineering design." }\end{array}$ \\
\hline Goal Programming (GP) & Can work with infinite alternatives & $\begin{array}{l}\text { Dependent upon other MCDM } \\
\text { processes }\end{array}$ & $\begin{array}{l}\text { Planning, scheduling and } \\
\text { controlling. }\end{array}$ \\
\hline
\end{tabular}

Now if the problem at hand is considered again the MCDM needed can be identified. So the characteristics of the problem is given below:

1. The problem possesses very limited number of criteria and alternatives. So GP model shouldn't be used.

2. The problem is related to selection of a location. This eliminates a few models.

3. The problem is binary in nature. Meaning each criteria is either better than other criteria or worse. There is no middle ground. This eliminates fuzzy model.

4. The solution should be such that it can be described in Layman's terms. This eliminates ELECTRE method.

5. The data provided had a big chance of being inconsistent because most of the data was gathered using survey. This eliminates case based reasoning. Here it must be noted that AHP includes a technique for identifying inconsistent data.

6. This research work aims to establish a single valid process for the selection of warehouse location. This eliminates ELECTRE I, ELECTRE II, ELECTRE III.

7. The solution selected must be optimal. As in the solution must be such that it optimizes all the resources to the fullest extent. This particular characteristic eliminates Grey theory.

So using the process of elimination it is evident that only AHP and TOPSIS are the most suited methods for solving the location related problem.

\subsection{Choice of Criteria}

After reviewing several literature of same kind 12 criteria were selected for implementing these processes. From these criteria 5 were chosen according to expert opinion

Unit Price: One of the main distinguishing characteristic of selecting a warehouse is unit price. It is basically the amount of money spent on a single unit kept in the warehouse. It can be determined by dividing the cost by the number of materials that can be kept in the warehouse. The reason why behind this distinguishing criteria is as the unit price increases the warehouse becomes more desirable and vice versa. The reason why this is favored in lieu of total cost, is that, even if total cost is less that doesn't paint the whole picture can be less 
maybe the cost is low but the number of items kept is low too.

Movement flexibility: Movement flexibility is basically how easily an item can be moved in and out of the warehouse. It is a subjective factor. Meaning the same warehouse may seem flexible to some and inflexible to someone else. So in order to determine movement flexibility for a warehouse the experts in the warehouse were interviewed. The experts were instructed to give thee warehouses a score of $0-4$.

Where the numbers symbolize really bad, bad, okay, good, very good respectively.

Layout: It is how much the layout of the buildings affect the warehouse. Layout was determined in the same way as movement flexibility. Again the experts were asked to give the warehouses a score of 0-4.

Distance from the main factory: This is a very important warehouse selection criteria as evident from how many papers selected this as a distinguishing criteria. This is important because as the distance increases, the transportation cost increases. Supply chain management becomes more difficult.

Stock holding capacity: This is one of the most important criteria for the selection of warehouse. Any person with common sense must understand that desirability of a warehouse is directly proportional to the stock holding capacity of the warehouse. But it also must be made sure that the products stored must not hinder the movement of the products. Otherwise the increasing of one criteria may end up decreasing other one.

\section{Application of the Selected MCDM Process}

\subsection{Performing AHP}

Now according to these formulas, normalized pairwise matrix is formed. First the importance level of chosen criteria is determined from survey. Then the criteria are compared pairwise. After that according to formula 1 normalized pairwise comparison matrix is formed.

Table 2. Significance of Pairwise Comparison Matrix Value.

\begin{tabular}{lll}
\hline Value & Definition & Significance \\
\hline 1 & Equally important & It means that the element in thee row is equally important as the element in the column. \\
3 & Moderately important & It means the criteria in the row is slightly more important than the criteria in the column. \\
5 & Strongly important & When the criteria in the row is significantly important than the criteria in the column. \\
7 & Absolutely important & When the criteria in the row is far more important than the criteria in the column. \\
$2,4,6,8$ & Intermediate values & If a compromise between the value are needed.
\end{tabular}

Now to normalize this pairwise matrix we perform the following calculation:

$$
\mathrm{N}_{\mathrm{ij}}=\frac{\mathrm{C}_{\mathrm{ij}}}{\sum_{\mathrm{i}}^{\mathrm{n}} \mathrm{C}_{\mathrm{ij}}}
$$

Here $\mathrm{i}$ and $\mathrm{j}$ are rows and columns respectively. $\mathrm{N}_{\mathrm{ij}}$ is normalized form of the pairwise equation. I and $\mathrm{j}$ can be between 1 and 5 because there are 5 criteria. Next it was time to determine the weight of the selected criteria. To determine that the following formula is implemented:

$$
\mathrm{W}_{\mathrm{i}}=\frac{\sum_{\mathrm{i}}^{\mathrm{n}} \mathrm{N}_{\mathrm{i}}}{\mathrm{n}}
$$

Here $\mathrm{i}$ is column. And $\mathrm{i}=1,2,3,4,5$. And $\mathrm{n}$ is the number of criteria selected. $\mathrm{N}_{\mathrm{i}}$ is the normalized matrix value. And $\mathrm{W}_{\mathrm{i}}$ is the criteria weight. In the same way alternative weight is determined. Alternative weight is depicted as $A_{i}$. Then score is determined and the alternative with the largest score is selected alternative.

$$
\text { score }=\sum \mathrm{W}_{\mathrm{i}} * \mathrm{~A}_{\mathrm{i}}
$$

Then the weighted sum value is determined and the ratio of weighted sum and criteria weight is calculated using the following formula:

$$
W S_{i}=C_{i} \times W_{i}
$$

$$
\mathrm{R}_{\mathrm{i}}=\frac{\mathrm{wS}}{\mathrm{W}_{\mathrm{i}}}
$$

Here $\mathrm{WS}_{\mathrm{i}}$ is the weighted sum value for $\mathrm{i}$ criterion. And $\mathrm{C}_{\mathrm{i}}$ and $\mathrm{W}_{\mathrm{i}}$ are pairwise comparison element and weight of criteria respectively.

$$
\begin{gathered}
\lambda_{\max }=\frac{\sum_{\mathrm{i}}^{\mathrm{n}} \mathrm{R}_{\mathrm{i}}}{\mathrm{n}} \\
\mathrm{CI}=\frac{\lambda_{\max }-\mathrm{n}}{\mathrm{n}-1} \\
C R=\frac{C I}{R I}
\end{gathered}
$$

Here CI is consistency index and CR is consistency ratio and RI is random consistency index. $\lambda_{\max }$ is maximum eigenvalue value. It is a validating principle of AHP. Random Index is found from the table below:

Table 3. Random index table.

\begin{tabular}{lllllll}
\hline $\mathbf{N}$ & $\mathbf{1}$ & $\mathbf{2}$ & $\mathbf{3}$ & $\mathbf{4}$ & $\mathbf{5}$ & $\mathbf{6}$ \\
\hline $\mathrm{RI}$ & 0 & 0 & .58 & .9 & 1.12 & 1.24 \\
\hline
\end{tabular}

Now according to these formulas, normalized pairwise matrix is formed. First the importance level of chosen criteria is determined from survey. Then the criteria are compared pairwise. After that according to formula 1 normalized pairwise comparison matrix is formed. 
Table 4. Pairwise Comparison for the Selected Criteria.

\begin{tabular}{llllll}
\hline Criteria & Unit price & Stock holding capacity & Average distance to factory & Flexibility & Layout \\
\hline Unit price & 1 & 1.2 & 1 & 3 & 2 \\
Stock holding capacity & 0.833333333 & 1 & 1 & 2.5 & 1.666666667 \\
Average distance to factory & 0.833333333 & 1 & 1 & 2.5 & 1.666666667 \\
Flexibility & 0.333333333 & 0.5 & 0.4 & 1 & 0.666666667 \\
Layout & 0.5 & 0.6 & 0.6 & 1.5 & 1 \\
Sum & 3.5 & 4.3 & 4 & 10.5 & 7 \\
\hline
\end{tabular}

Table 5. Normalized Pairwise comparison matrix.

\begin{tabular}{lllllll}
\hline Criteria & Unit price & Stock holding capacity & Average distance to factory & Flexibility & Layout & Criteria weight \\
\hline Unit price & 0.2857 & 0.2791 & 0.25 & 0.2857 & 0.2857 & 0.2772 \\
Stock holding capacity & 0.2381 & 0.2326 & 0.25 & 0.2381 & 0.2381 & 0.2393 \\
Average distance to factory & 0.2381 & 0.2325 & 0.25 & 0.2381 & 0.2381 & 0.2393 \\
Flexibility & 0.0952 & 0.1162 & 0.1 & 0.0952 & 0.0952 & 0.1003 \\
Layout & 0.1428 & 0.1395 & 0.15 & 0.1428 & 0.1428 & 0.1436 \\
\hline
\end{tabular}

In order to perform pairwise comparison with respect to of the warehouses with respect to each criteria, first the criteria are divided into two factions. Such as value adding and value declining. If the abundance of a certain is positive for the warehouse it is thought of as value adding criteria while if increased value of a certain criteria is unwanted then that particular criteria is thought of as value declining criteria. For example, a large value of stock holding capacity is positive for the warehouse while a large value of unit price is not so. Hence unit price is a value declining criteria and stock holding capacity is value adding. In value declining criteria content of column is divided by content of row and for value adding criteria content of row is divided by content of column.

Table 6. Pairwise Comparison among Alternatives With Respect to Each Criteria.

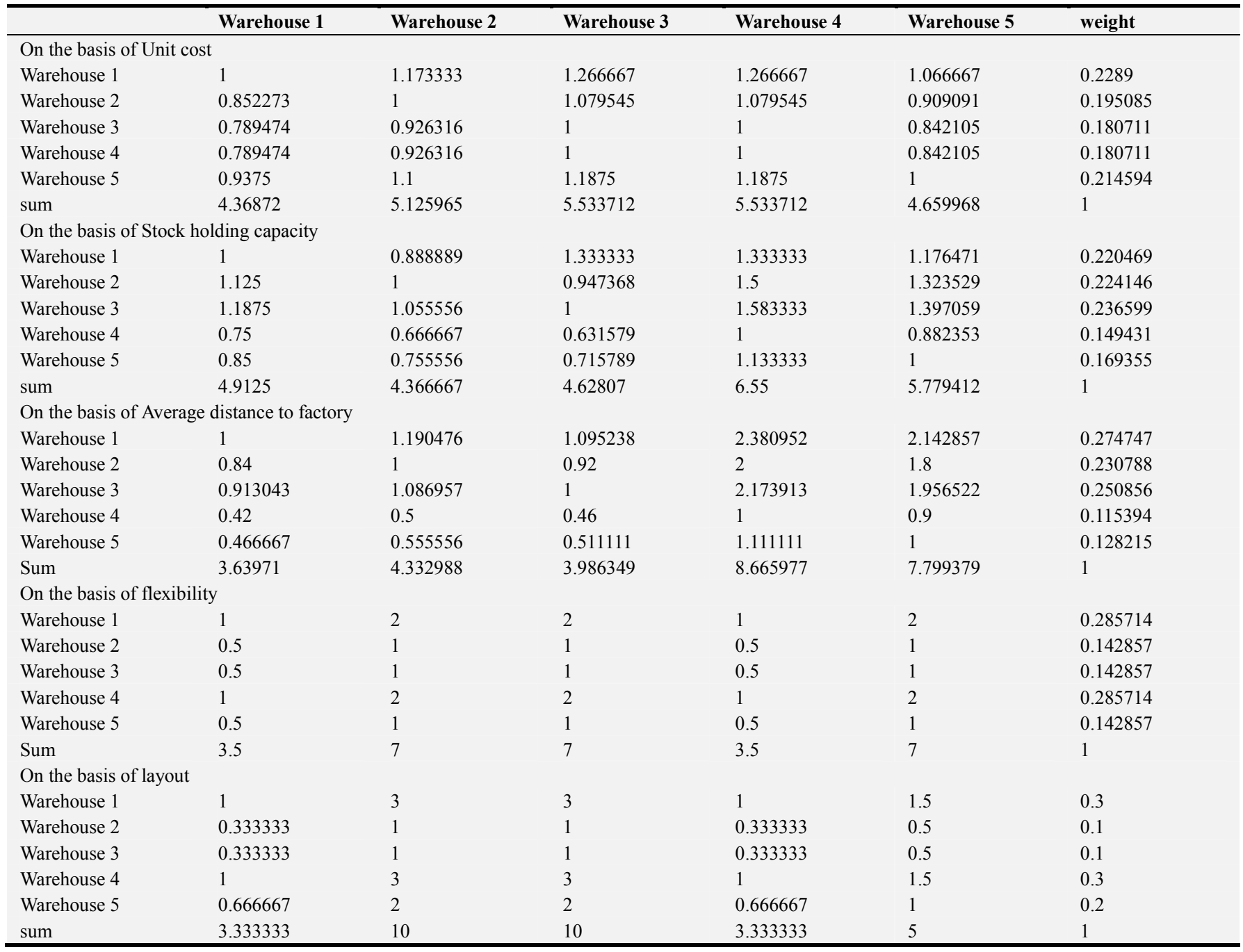


Table 7. Priority score determination.

\begin{tabular}{|c|c|c|c|c|c|c|}
\hline \multirow{2}{*}{ Criteria } & \multirow{2}{*}{$\begin{array}{l}\text { Criteria } \\
\text { weight }\end{array}$} & \multicolumn{5}{|c|}{ Priority score for alternatives } \\
\hline & & Warehouse 1 & Warehouse 2 & Warehouse 3 & Warehouse 4 & Warehouse 5 \\
\hline Unit price & 0.277242525 & 0.228899993 & 0.195085221 & 0.180710521 & 0.180710521 & 0.214593744 \\
\hline Stock holding capacity & 0.239368771 & 0.220469281 & 0.224146213 & 0.23659878 & 0.149430809 & 0.169354916 \\
\hline Average distance to factory & 0.239368771 & 0.274747153 & 0.230787609 & 0.250856096 & 0.115393804 & 0.128215338 \\
\hline Flexibility & 0.10039861 & 0.285714286 & 0.142857143 & 0.142857143 & 0.285714286 & 0.142857143 \\
\hline Layout & 0.143621262 & 0.3 & 0.1 & 0.1 & 0.3 & 0.2 \\
\hline Score & & 0.253771857 & 0.191687654 & 0.195486901 & 0.185263079 & 0.173790448 \\
\hline Ranking & & 1 & 3 & 2 & 4 & 5 \\
\hline
\end{tabular}

\subsection{Validation Test for AHP}

Comparing the alternatives on basis of some criteria it is found that warehouse 1 is the most reckonable for this case.

Table 8. Consistency Index Determination.

\begin{tabular}{|c|c|c|c|c|c|c|c|}
\hline Criteria & Unit price & $\begin{array}{l}\text { Stock holding } \\
\text { capacity }\end{array}$ & $\begin{array}{l}\text { Average distance } \\
\text { to factory }\end{array}$ & Flexibility & Layout & $\begin{array}{l}\text { Weighted } \\
\text { sum value }\end{array}$ & Ratio \\
\hline Unit price & 0.277242525 & 0.287243 & 0.239369 & 0.301196 & 0.287243 & 1.3922924 & 5.021929 \\
\hline Stock holding capacity & 0.231035437 & 0.239369 & 0.239369 & 0.2509967 & 0.239369 & 1.2001384 & 5.013764 \\
\hline Average distance to factory & 0.231035437 & 0.239369 & 0.239369 & 0.2509967 & 0.239369 & 1.2001384 & 5.013764 \\
\hline Flexibility & 0.092414175 & 0.119684 & 0.095748 & 0.1003987 & 0.095748 & 0.5039922 & 5.01991 \\
\hline Layout & 0.138621262 & 0.143621 & 0.143621 & 0.150598 & 0.143621 & 0.7200831 & 5.013764 \\
\hline
\end{tabular}

Consistency index

$$
\mathrm{CI}=\frac{\lambda_{\max }-\mathrm{n}}{\mathrm{n}-1}
$$

Consistency Ratio

$$
C R=\frac{C I}{R I}
$$

$\lambda_{\max }=5.016626$

$\mathrm{CI}=.004156$

$\mathrm{CR}=.003711$. So the determined value is valid.

\subsection{Performing TOPSIS}

The following formulas are needed for the determination of optimum warehouse location using TOPSIS:

At first the real values are put and then they are normalized using the following equation:

$$
\overline{X_{l j}}=\frac{X_{i j}}{\sqrt{\sum_{j=1}^{m} X_{i j}^{2}}}
$$

Here $\overline{X_{l j}}$ is the normalized element. $\mathrm{J}$ is the number of column in this case $\mathrm{j}=1,2,3$. And $\mathrm{X}_{\mathrm{ij}}$ is the non-normalized element in the previously described matrix. Then the weighted normalized matrix is determined using the following equation:

$$
V_{i j}=\overline{X_{l j}} \times W_{j}
$$

Here $\mathrm{W}_{\mathrm{j}}$ is the criteria weight. The criteria weight has already been determined in the previous section namely the AHP calculation section. $V_{i j}$ is the weighted normalized matrix element. Then the ideal best and ideal worst value are determined. For a beneficial criteria such as stick holding capacity, ideal best value is the maximum value in the column and for a non-beneficial criteria it is the smallest value. Ideal worst value is the direct opposite of ideal best value and determined in the directly opposite principle. After that the eucledian distances from the ideal best and ideal worst value are determined and the formula to determine them are written below:

$$
\begin{gathered}
\mathrm{S}_{\mathrm{i}}^{+}=\sqrt{\sum\left(\mathrm{V}_{\mathrm{ij}}-\mathrm{V}_{\mathrm{j}}^{+}\right)^{\wedge} 2} \\
\mathrm{~S}_{\mathrm{i}}^{-}=\sqrt{\sum\left(\mathrm{V}_{\mathrm{ij}}-\mathrm{V}_{\mathrm{j}}^{-}\right)^{\wedge} 2}
\end{gathered}
$$

Here $\mathrm{S}_{\mathrm{i}}^{+}$and $\mathrm{S}_{\mathrm{i}}^{-}$are eucledian distance from the ideal best and ideal worst value. Then the performance score is determined. The alterative with the largest performance score

\begin{tabular}{|c|c|c|c|c|c|}
\hline \multicolumn{6}{|l|}{ The obtained data table } \\
\hline $\begin{array}{ll}\text { Warehouse } & \text { Criteria } \\
\end{array}$ & Unit Price & Stock holding capacity & Average distance to factory & Flexibility & Layout \\
\hline Warehouse 1 & 0.75 & 80000 & 210 & 4 & 3 \\
\hline Warehouse 2 & 0.88 & 90000 & 250 & 2 & 1 \\
\hline Warehouse 3 & 0.95 & 95000 & 230 & 2 & 1 \\
\hline Warehouse 4 & 0.95 & 60000 & 500 & 4 & 3 \\
\hline Warehouse 5 & 0.8 & 68000 & 450 & 2 & 2 \\
\hline
\end{tabular}
selected as the choice. The performance score is determined in the following equation:

$$
\mathrm{P}^{\mathrm{ij}}=\frac{\mathrm{S}_{\mathrm{i}}^{-}}{\mathrm{S}_{\mathrm{i}}^{+}+\mathrm{S}_{\mathrm{i}}^{-}}
$$

Table 9. Obtained Data Table. 
This table was basically the value found from the experts from the energypac garments. After that the normalization was performed.

Table 10. Normalized matrix

\begin{tabular}{|c|c|c|c|c|c|}
\hline \multicolumn{6}{|l|}{ Normalized matrix } \\
\hline $\begin{array}{ll}\text { Criteria } \\
\text { Warehouse }\end{array}$ & Unit Price & Stock holding capacity & Average distance to factory & Flexibility & Layout \\
\hline Warehouse 1 & 0.385661 & 0.521585 & 0.525822 & 0.816497 & 0.904534 \\
\hline Warehouse 2 & 0.452509 & 0.586783 & 0.625979 & 0.408248 & 0.301511 \\
\hline Warehouse 3 & 0.488505 & 0.619382 & 0.575901 & 0.408248 & 0.301511 \\
\hline Warehouse 4 & 0.488505 & 0.336733 & 0.639137 & 0.603023 & 0.612372 \\
\hline Warehouse 5 & 0.411372 & 0.381631 & 0.575224 & 0.301511 & 0.408248 \\
\hline
\end{tabular}

Table 11. Weighted Normalized Matrix.

\begin{tabular}{|c|c|c|c|c|c|}
\hline Warehouse $\quad$ Criteria & Unit Price & Stock holding capacity & Average distance to factory & Flexibility & Layout \\
\hline Warehouse 1 & 0.106922 & 0.124851 & 0.125865 & 0.081975 & 0.12991 \\
\hline Warehouse 2 & 0.125455 & 0.140458 & 0.14984 & 0.040988 & 0.043303 \\
\hline Warehouse 3 & 0.135434 & 0.148261 & 0.137853 & 0.040988 & 0.043303 \\
\hline Warehouse 4 & 0.135434 & 0.080603 & 0.15299 & 0.060543 & 0.08795 \\
\hline Warehouse 5 & 0.11405 & 0.091351 & 0.137691 & 0.030271 & 0.058633 \\
\hline
\end{tabular}

Table 12. Ideal Best and Ideal Worst Value Determination.

\begin{tabular}{llllll}
\hline $\mathrm{V}+$ & 0.10692 & 0.14826 & 0.15299 & 0.08198 & 0.12991 \\
$\mathrm{~V}-$ & 0.13543 & 0.0806 & 0.12587 & 0.03027 & 0.0433 \\
\hline
\end{tabular}

Table 13. Priority Determination.

\begin{tabular}{lllll}
\hline Ware House & S+ & S- & P & Ranking \\
\hline W1 & 0.035829 & 0.113775 & 0.760508 & 1 \\
W & 0.097954 & 0.066119 & 0.402985 \\
W & 0.101108 & 0.069542 & 0.407511 & 3 \\
W4 & 0.087238 & 0.060377 & 0.409015 & 2 \\
W5 & 0.106195 & 0.030784 & 0.224733 & 5 \\
\hline
\end{tabular}

So, according to TOPSIS, again the selected warehouse was warehouse 1 among the other alternatives on basis of those criteria that were analyzed before.

\section{Result and Discussion}

Although this is the main finding associated with the research work, the importance of the research work lie elsewhere. This research work has by itself fulfilled a few important objectives. Not only has it demonstrated how to perform two major MCDM processes but also it has shown how to choose these processes according to the circumstances. Another important objective it has fulfilled is by accumulating the mathematical formulation associated with the processes. To our knowledge no single research paper has accomplished all these in one research work

Table 14. Level of preference of five warehouses according to the two methods.

\begin{tabular}{|c|c|c|c|c|c|}
\hline Tools Warehouse & Warehouse 1 & Warehouse 2 & Warehouse 3 & Warehouse 4 & Warehouse 5 \\
\hline AHP & 1 & 3 & 2 & 4 & 5 \\
\hline TOPSIS & 1 & 4 & 3 & 2 & 5 \\
\hline
\end{tabular}

After that the calculation for all the methods were performed, the warehouse selected was the first one in both cas5es since finding the most suitable warehouse location was the objective of the research. This result can be thought of as satisfactory.

\section{Conclusions}

What this paper set put to do is finding out the best possible warehouse for a certain garments industry. In the process gain a thorough knowledge on several multi attribute decision making process. This research work also managed to properly implement the selected MCDM processes and document the thorough process. This paper achieved data from an industry facing similar problem. After that the data regarding the selected criteria had to be gained from the experts in the field. After careful input and calculation of data this research work managed to find out that according to all the MCDM processes the first option was the most optimum.

The impact of this particular research is versatile to say the least. Although the research work is not unique it in many 
ways embodies various research works in the same field. This research work has been able to analyze MCDM processes to choose the suitable one for the situation in hand. After that the implementation of the processes took place which resulted in the choosing of one of the warehouses.

\section{Recommendations}

1. If the expert's opinions about the level of importance stay unchanged then the chosen process should be used while determining the appropriate warehouse.

2. If the experts feel that the level of importance of any criteria should be somewhere between the designated numbers then fuzzy methods should be employed.

3. If at any moment the chosen warehouse for several processes prove to be different then BORDA method needs to be employed for tie break.

\section{References}

[1] Aruldoss, M., Lakshmi, T. M., \& Venkatesan, V. P. (2013). A survey on multi criteria decision making methods and its applications. American Journal of Information Systems, 1 (1), $31-43$.

[2] Özcan, T., Çelebi, N. and Esnaf, Ş., 2011. Comparative analysis of multi-criteria decision making methodologies and implementation of a warehouse location selection problem. Expert Systems with Applications, 38 (8), pp. 9773-9779.

[3] Chen, C. (2009). A decision model of field depot location based on the centrobaric method and analytic hierarchy process (AHP). International Journal of Business and Management, 4 (7), 71-75.

[4] Akalin, M., Turhan, G., \& Sahin, A. (2013). The Application of AHP Approach for Evaluating Location Selection Elements for Retail Store. International Journal of Research in Business and Social Science (2147-4478), 2 (4), 01-20.

[5] Uma Devi, K., Elango, C. and Rajesh, R., 2012. Vendor selection using AHP. Procedia engineering, 38, pp. 19461949.

[6] Velasquez, M. and Hester, P. T., 2013. An analysis of multicriteria decision making methods. International Journal of Operations Research, 10 (2), pp. 56-66.

[7] Dobrota, M., Macura, D., \& Šelmić, M. (2015, May). Multi criteria decision making for distribution center location selection-Serbia case study. In 2nd Logistics International Conference (pp. 32-37).

[8] Dağdeviren, M., Yavuz, S., \& Kılınç, N. (2009). Weapon selection using the AHP and TOPSIS methods under fuzzy environment. Expert Systems with Applications, 36 (4), 81438151.

[9] Senthil, S., Srirangacharyulu, B. and Ramesh, A., 2014. A robust hybrid multi-criteria decision making methodology for contractor evaluation and selection in third-party reverse logistics. Expert Systems with Applications, 41 (1), pp. 50-58.

[10] Behzadian, M., Otaghsara, S. K., Yazdani, M., \& Ignatius, J. (2012). A state-of the-art survey of TOPSIS applications. Expert Systems with applications, 39 (17), 13051-13069.

[11] Colson, G., \& Dorigo, F. (2004). A public warehouses selection support system. European Journal of Operational Research, 153 (2), 332-349.

[12] Dervitsiotis, K. N., 1981. Operations management. McGrawHill Companies.

[13] Erkan, T. E., \& Can, G. F. (2014). Selecting the best warehouse data collecting system by using AHP and FAHP methods. Technical Gazette, 21 (1), 87-93.

[14] MacCarthy, B. L., \& Atthirawong, W. (2003). Factors affecting location decisions in international operations-a Delphi study. International Journal of Operations \& Production Management, 23 (7), 794-818.

[15] Emeç, Ş., \& Akkaya, G. (2018). Stochastic AHP and fuzzy VIKOR approach for warehouse location selection problem. Journal of Enterprise Information Management, 31 (6), 950962.

[16] Dey, B., Bairagi, B., Sarkar, B., \& Sanyal, S. K. (2016). Warehouse location selection by fuzzy multi-criteria decision making methodologies based on subjective and objective criteria. International Journal of Management Science and Engineering Management, 11 (4), 262-278.

[17] Boltürk, E., Çevik Onar, S., Öztayşi, B., Kahraman, C., \& Goztepe, K. (2016). Multi-attribute warehouse location selection in humanitarian logistics using hesitant fuzzy AHP. International Journal of the Analytic Hierarchy Process, 8, 271-298.

[18] Raut, R. D., Narkhede, B. E., Gardas, B. B., \& Raut, V. (2017). Multi-criteria decision making approach: a sustainable warehouse location selection problem. International Journal of Management Concepts and Philosophy, 10 (3), 260-281. 